\title{
Yam Extracts Increase Cell Proliferation and Bone Matrix Protein Collagen Synthesis of Murine Osteoblastic MC3T3-E1 Cells
}

\author{
Mee-Young Shin ${ }^{1}$, Ethel H. Alcantara', Youn-Moon Park ${ }^{2}$, Soon-Tae Kwon ${ }^{3}$, and In-Sook Kwun ${ }^{1 \dagger}$ \\ ${ }^{1}$ Department of Food Science and Nutrition, College of Human Ecology, ${ }^{2}$ Department of Food Science and Biotechnology, \\ ${ }^{3}$ Department of Horticulture and Breeding, College of Natural Sciences, Andong National University, Gyeongbuk 760-749, Korea
}

\begin{abstract}
Yam extracts (Dioscorea batatas) have been reported to possess a variety of functions. However, studies on its osteogenic properties are limited. In this study, we investigated the effect of ethanol and water extracts on osteoblast proliferation and bone matrix protein synthesis, type I collagen and alkaline phosphatase (ALP), using osteoblastic MC3T3-E1 cell model. MC3T3-E1 cells were cultured with yam ethanol and water extracts $(0 \sim 30$ $\mathrm{mg} / \mathrm{L}$ ) within 39 days of osteoblast differentiation period. Cell proliferation was measured by MTT assay. Bone matrix proteins were assessed by the accumulation of type I collagen and ALP activity by staining the cell layers for matrix staining. Also, the secreted (media) matrix protein concentration (type I collagen) and enzyme activity (ALP) were measured colorimetrically. Yam ethanol and water extracts stimulated cell proliferation within the range of $15 \sim 30 \mathrm{mg} / \mathrm{L}$ at 15 day treatment. The accumulation of type I collagen in the extracellular matrix, as well as secreted collagen in the media, increased with increasing doses of yam ethanol $(3 \sim 15 \mathrm{mg} / \mathrm{L})$ and water (3 $30 \mathrm{mg} / \mathrm{L})$ extracts. ALP activity was not affected by yam ethanol extracts. Our results demonstrated that yam extracts stimulated osteoblast proliferation and enhanced the accumulation of the collagenous bone matrix protein type I collagen in the extracellular matrix. These results suggest that yam extracts may be a potential activator for bone formation by increasing osteoblast proliferation and increasing bone matrix protein type I collagen. Before confirming the osteogenic action of yam, further studies for clarifying how and whereby yam extracts can stimulate this ostegenesis action are required.
\end{abstract}

Key words: yam (Dioscorea batatas), MC3T3-E1 cells, proliferation, type I collagen, alkaline phosphatase (ALP)

\section{INTRODUCTION}

Bone formation is characterized by the formation of a collagen-rich extracellular matrix after which, expression of genes associated with differentiated osteoblast follows; alkaline phosphatase (ALP) and parathyroid hormone protein receptor are early markers while osteopontin and osteocalcin are late markers (1). Therefore, bone formation including extracellular matrix mineralization by differentiated osteoblasts is an exquisitely complex process that follows a temporal sequence of gene expression that eventually culminates in the mineralization of the matrix secreted by osteoblasts. Unlike any other tissues, bones are continuously being remodelled to maintain constant bone volume via a delicate balance between bone formation by osteoblasts and bone resorption by osteoclasts. An increase in bone resorption over bone formation can lead to most adult skeletal diseases including osteoporosis, the most prevalent metabolic bone disorder (2). Until recently, therapies aimed to ameliorate skeletal diseases, most notably osteoporosis, are usually focused on diminishing resorption rather than increasing bone formation. However, more concern is focused recently in the determination of therapeutics that might aid in bone formation by osteoblast that could provide more useful approach in the treatment of bone loss in osteoporosis.

There has been an increasing interest in the utilization of food-origin products in the treatment of diseases since they are basically safe and inexpensive. Moreover, numerous edible food-origin products are showing tremendous potential for the treatment of bone-related diseases. For example, it has been reported that a number of common vegetables including onion, garlic and parsely, can inhibit bone resorption in ovariectomized rats (3). Curcumin, which is an active compound of yellow spicy turmeric, have been reported to suppress receptor activator of NF- $\mathrm{kB}$ ligand (RANKL) and consequent osteoclastogenesis (4).

Yams (Dioscorea batatas) are tuberous vines that are widely distributed in East Asia including China, Korea, and Japan. Plants of the genus Dioscorea have been used for edible starch food sources and traditionally used in 
oriental societies. In Korea, yam is consumed as medicinal and functional food. Recently, several studies have suggested the potential of several species of yam to inhibit bone resorption, as well as to promote bone formation. The phytochemicals from yam such as glycosides, lignans, diosgenin, and dioscin have all been reported to have anti-osteoporotic activity both in vitro and in vivo (5-8). In our previous study, we reported that diosgenin, a major component of yam, showed osteogenic action through upregulating bone-specific transcription factor Runx 2 and bone matrix protein synthesis in osteoblastic MC3T3-E1 cells (9). However, the in vitro effect of yam extracts on osteoblastic MC3T3-E1 cell proliferation and their effect on the accumulation of type I collagen and ALP, the bone matrix proteins crucial for extracellular matrix mineralization, have not been reported.

This study aimed to assess the osteogenic properties of extracts of yams grown locally within the vicinity of Andong, Kyungbook Province, South Korea. Specifically, this study was undertaken to examine the effect of various concentrations of yam ethanol and water extracts on the cell proliferation and synthesis of the bone matrix proteins, type I collagen and alkaline phosphatase (ALP), using murine osteoblastic MC3T3-E1 cell model. Findings from this study might provide an insight into the potential role of yam extracts in enhancing bone formation.

\section{MATERIALS AND METHODS}

\section{Reagents}

Antibodies for target proteins (type 1 collagen) were obtained from Santa Cruz Biotechnology (Santa Cruz, CA, USA) while antibody for loading control (GAPDH) was obtained from Cell Signaling (Beverly, MA, USA). Cell culture reagents including $\alpha$-minimum essential media $(\alpha$-MEM), fetal bovine serum, and penicillin/streptomycin were obtained from Gibco ${ }^{\circledR}$ (Grand Island, NY, USA). Sodium pyruvate, $\beta$-glycerophosphate, L-ascorbic acid were all obtained from Sigma (St. Louis, MO, USA). The BCA Protein assay kit, RIPA buffer, and the Super Signal West Pico Chemiluminescence detection reagents were from Pierce Biotechnology (Rockford, IL, USA) while the PVDF membrane was obtained from Millipore (Billerica, MA, USA). All other reagents used were from Sigma.

\section{Yam extracts preparation}

Yam (Dioscorea batatas) grown locally within the vicinity of Andong, Kyungbook Province, South Korea was provided by Bookwho Nonghyup which is the major area for yam production in Andong. Yam was extracted with 2 liters of $80 \%$ methanol for 48 hours. The extracted yam solvent was filtered and concentrated by rotary evaporation. After concentration, the extracted yam was graduated in ethanol (EtOH), hexane (Hex), chloroform $\left(\mathrm{CH}_{3} \mathrm{Cl}_{3}\right)$, ethyl acetate (EtOAc), butanol $(\mathrm{BuOH})$ and water $\left(\mathrm{H}_{2} \mathrm{O}\right)$.

\section{Cell culture}

Mouse osteoblastic MC3T3-E1 cells were seeded at a density of $1 \times 10^{3}$ cells $/ \mathrm{mL}$ and cultured in regular growth culture media containing $\alpha$-minimum essential medium ( $\alpha$-MEM), supplemented with $10 \%$ fetal bovine serum, $1 \mathrm{mM}$ sodium pyruvate, and 100 units/L penicillin and $100 \mathrm{mg} / \mathrm{L}$ streptomycin in a humidified atmosphere of $5 \% \mathrm{CO}_{2}$ at $37^{\circ} \mathrm{C}$. At $80 \%$ confluence, the cells were cultured in differentiation media as growth media supplemented with $10 \mathrm{mM} \beta$-glycerolphosphate and $50 \mu \mathrm{g} / \mathrm{mL}$ L-ascorbic acid as osteogenic differentiation medium. Cells were treated with various yam extracts ( $\mathrm{EtOH}, \mathrm{Hex}, \mathrm{CH}_{3} \mathrm{Cl}_{3}$, EtOAc, $\mathrm{BuOH}$, and $\mathrm{H}_{2} \mathrm{O}$ ) for cell proliferation assay. Also cells were treated with $1 \sim 30 \mathrm{mg} / \mathrm{L}$ of yam ethanol and water extracts for the assay for type I collagen and ALP. The medium was changed every $2 \sim 3$ days. The cells cultured in normal osteogenic differentiation medium without yam extracts were used as osteogenic control (OSM).

\section{Cell proliferation assay}

Cell proliferation was determined by MTT assay. Briefly, cells $\left(1 \times 10^{3}\right.$ cells/well in 96 -well plate $)$ were maintained in growth media for $24 \mathrm{hr}$ at $5 \% \mathrm{CO}_{2}, 37^{\circ} \mathrm{C}$. At $90 \%$ confluence, the cells were treated with various concentrations $(1,3,5,10,15$ and $30 \mathrm{mg} / \mathrm{L})$ of yam extracts for 6,15 and 39 days. Following the respective time treatment, MTT was added to the cell cultures and samples were incubated at $37^{\circ} \mathrm{C}$ for $3 \mathrm{hr}$. The production of formazan by the reduction of MTT was measured for the indication of mitochondrial dehydrogenases enzyme activity of viable cells. Absorbance for enzyme products was measured at $570 \mathrm{~nm}$ using an optical 96-well microplate reader (Sunrise Absorbance Reader, Tecan, GmbH, Grödig, Austria).

\section{Protein quantification}

Osteoblastic MC3T3-E1 cells were cultured on 6-well plates and treated with $100 \mathrm{mg} / \mathrm{L}$ of yam water, butanol, ethanol, and hexane extracts for 6 days. Cells cultured using normal osteogenic medium (OSM) were used as control. After treatment, cells were harvested and lysed with RIPA buffer $(150 \mathrm{mM} \mathrm{NaCl}, 1 \%$ Nonidet P-40, $1 \%$ sodium deoxycholate, $0.1 \%$ SDS, $25 \mathrm{mM}$ Tris- $\mathrm{HCl}, \mathrm{pH}$ 7.6, supplemented with $1 \%$ protease inhibitor). Protein 
amounts were determined using Pierce BCA assay kit.

\section{Westem blot analysis}

Whole cell lysates $(30 \mu \mathrm{g})$ were separated by $10 \%$ SDS-PAGE and transferred to PVDF membrane by Immobilon-P. The membranes were blocked with 5\% non-fat milk and incubated with the primary antibodies for type I collagen and GAPDH. The membranes were then incubated with secondary antibody conjugated to horseradish peroxidase and were developed using Super Signal West Pico Chemiluminescence detection reagents.

\section{Collagen measurement}

Medium collagen concentration measurement: The amount of medium collagen was measured using the Picro-Sirius red method. Fifty micro liters each of the collagen standard, protein and medium samples were added on each well of 96-well plate and were allowed to dry at $37^{\circ} \mathrm{C}$ in humidified atmosphere for 24 hours for denaturation of the proteins. After drying, the wells were washed with $200 \mu \mathrm{L}$ distilled water and $100 \mu \mathrm{L}$ of $0.1 \%$ Picro-Sirius red dye in picric acid was added on each well to combine with the connective protein collagen. The samples and standards were then incubated with the dye for 1 hour at $37^{\circ} \mathrm{C}$. After incubation, the samples and standards were washed three times with 200 $\mu \mathrm{L}$ of $10 \mathrm{mM} \mathrm{HCl}$ to remove the unbound dye. Finally, the bound collagen was dissolved by adding $200 \mu \mathrm{L}$ of $0.1 \mathrm{M} \mathrm{NaOH}$ for 5 minutes. The samples and standards were then transferred to a clean 96-well plate and absorbance was read at $540 \mathrm{~nm}$.

Cell matrix collagen staining: The synthesis of collagen was assessed by staining with Van Gieson. Cells were washed with distilled water and were allowed to dry completely. The cells were fixed with $2 \%$ formaldehyde at $4^{\circ} \mathrm{C}$ for 15 minutes. The cells were then washed twice with distilled water and stained with Van Gieson reagent for 15 minutes. Excess dye was removed by washing with at least three changes of distilled water. Collagen in the extracellular matrix is stained red.

\section{ALP activity measurement}

Medium ALP activity: Medium ALP activity was measured in cells treated with $1,3,5,10,15$ and $30 \mathrm{mg} / \mathrm{L}$ yam ethanol and water extracts for 39 days. Media were collected for the measurement of the secreted ALP. The ALP activity in media was measured using $p$-nitrophenyl phosphate as substrate and the product of enzyme activity, $p$-nitrophenyl, was measured as optical absorbance at $405 \mathrm{~nm}$ as previously described (9). The activity of medium ALP was expressed as nmol PNP ( $p$-nitrophenyl) $/ \mathrm{mL}$ medium/minute, which showed ALP activity as enzyme products produced per sample amount
$(\mathrm{mL})$ per minute from the substrate.

Cell matrix ALP staining: Cultured cells were rinsed with phosphate buffer saline (PBS, pH 7.4) and fixed with $2 \%$ formaldehyde. The cells were stained using Naphthol As-Mx phosphate disodium salt as a substrate for enzyme activity, $N, N$-dimethyl formamide, and fast red salt as dye for $30 \mathrm{~min}$ at $37^{\circ} \mathrm{C}$, or until yellow color appeared. After washing with PBS, the cells were photographed. The products of ALP activity were stained red as an indicator for the products of enzyme activity.

\section{Statistical analysis}

Data were analyzed using software SPSS 18.0. Values for cell proliferation, ALP activity and collagen concentration are presented as mean \pm SEM. The data analysis was performed using one way ANOVA and Tukey's HSD test was used as post hoc test if significance was detected among the treatments at the level of $p<0.05$.

\section{RESULTS}

\section{Cell proliferation of various yam extracts and expre- ssion of type I collagen}

The effect of various yam extracts $(100 \mathrm{mg} / \mathrm{L})$ on the proliferation of osteoblastic MC3T3-E1 cells was determined using MTT assay at 1 and 5 days of treatment (Fig. 1A). Cell proliferation was significantly higher in ethyl acetate, ethanol, water, and hexane extracts, compared to chloroform and butanol after 1 day treatment. However, extending the treatment up to 5 days showed a decrease in cell proliferation of ethyl acetate extract, while ethanol and water extracts showed consistently higher proliferation hence they are used for succeeding experiments. The expression of type 1 collagen as affected by extracts was analyzed by Western blotting after 6 days treatment (Fig. 1B). Butanol extract interestingly showed the highest type I collagen expression albeit its lower proliferation compared with other extracts while ethanol and water extracts both showed higher type I collage protein expression than the normal osteogenic control (OSM).

\section{Cell proliferation of yam ethanol and water extracts}

Using our proliferation and protein expression data described in Fig. 1 above, we decided to utilize yam ethanol and water extracts for further experiments. The effects of serial concentrations $(1 \sim 30 \mathrm{mg} / \mathrm{L})$ of both yam ethanol and water extracts on the proliferation of MC3T3E1 cells for $6,13,15$, and 39 days treatment were examined using MTT assay (Fig. 2A \& B). At 6 days treatment, both yam ethanol and water extract slightly stimulated proliferation but the increase was not statistically significant. A significant and dose-dependent stimulation 

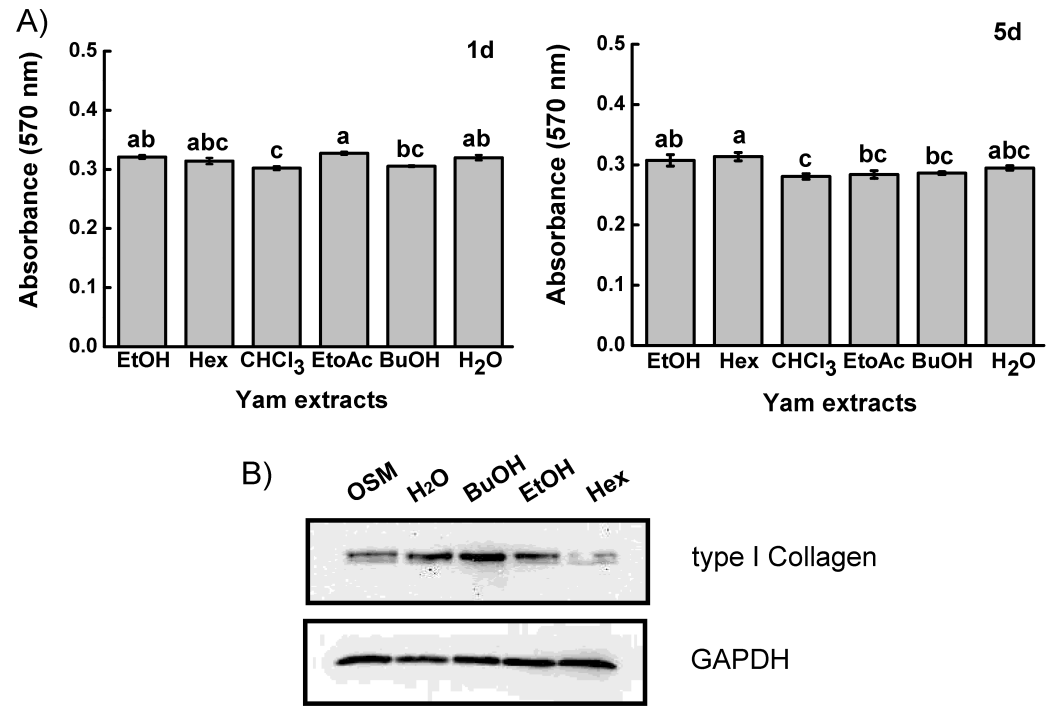

type I Collagen

GAPDH
Fig. 1. Effect of various yam extracts on osteoblastic MC3T3-E1 cell proliferation (A) and type I collagen expression (B). (A) At 90\% confluence, MC3T3-E1 cells were treated with various yam extracts $(100 \mathrm{mg} / \mathrm{L})$ for 1 and 5 days and cell proliferation was measured by MTT assay. The results are presented as absorbance at $570 \mathrm{~nm}$ which is the indirect indication of the intensity of live cells. The effect of the different yam extracts for cell proliferation was analyzed by one-way ANOVA at $\mathrm{p}<0.05$ followed by Tukey as post hoc test. Different superscripts indicated significant differences among various yam extract treatments $(n=6)$. (B) Type I collagen protein expression was analyzed by Western blot after 6 days yam extracts treatment $(100 \mathrm{mg} / \mathrm{L})$. EtOH: ethanol, Hex: hexane, $\mathrm{CHCl}_{3}$ : chloroform, EtoAc: ethyl acetate, $\mathrm{BuOH}$ : butanol, $\mathrm{H}_{2} \mathrm{O}$ : water, OSM: normal osteogenic media.
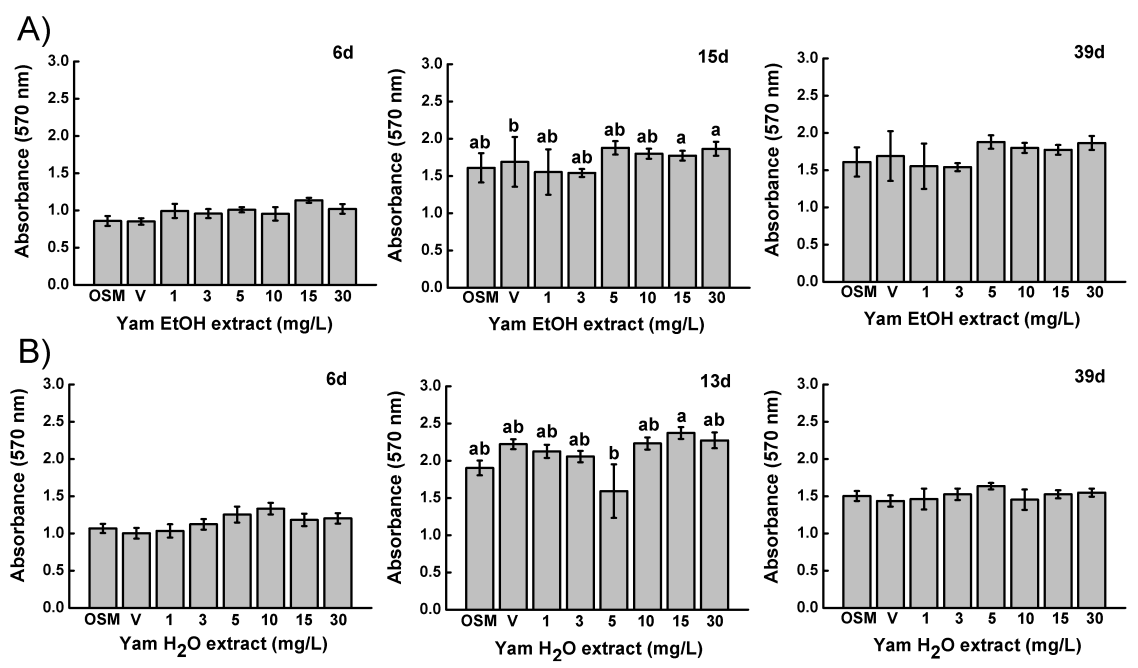

Fig. 2. Dose-dependent effect of yam ethanol (A) and water (B) extracts on osteoblastic MC3T3-E1 cell proliferation and protein synthesis (C). (A, B) Cell proliferation was measured by MTT assay and presented as absorbance at $570 \mathrm{~nm}$. The effect of the different yam extracts was analyzed by one-way ANOVA at $\mathrm{p}<0.05$ followed by Tukey as post hoc test. Different superscripts indicated significant differences among treatments $(n=6)$. V: vehicle. (C) Protein concentration was measured by BCA protein assay. No significant difference in protein contents with respect to yam extracts treatment was observed $(\mathrm{n}=3)$. EtOH: ethanol, $\mathrm{H}_{2} \mathrm{O}$ : water, OSM: normal osteogenic media.

of proliferation was observed at 15 days treatment for ethanol and at 13 days treatment for water extracts. No significant differences on proliferation were observed on both yam ethanol and water extracts after extending the treatment to 39 days. The protein synthesis by osteoblastic cells treated by yam ethanol and water extracts was measured by BCA protein assay after 6 days treatment (Fig. 2C). The protein synthesis showed the trend of higher protein content as observed with yam ethanol extract treatment, even without statistical significance.

\section{Collagen synthesis and secretion}

The effect of yam ethanol and water extracts on the accumulation of collagen in the extracellular matrix was measured by Van Gieson staining at 15 days (Fig. 3A). After 15 days treatment, yam ethanol extract dose-dependently increased collagen accumulation up to $15 \mathrm{mg}$ / $\mathrm{L}$, but increasing yam ethanol extract concentration to $30 \mathrm{mg} / \mathrm{L}$ decreased collagen accumulation. On the other hand, yam water extracts dose-dependently increased collagen accumulation from $3 \sim 30 \mathrm{mg} / \mathrm{L}$ (Fig. 3A). The amount of collagen secreted into the media was measured after 39 days treatment. Both yam ethanol and water extracts dose-dependently increased the secreted collagen, and this pattern is more prominent in yam ethanol 
A)
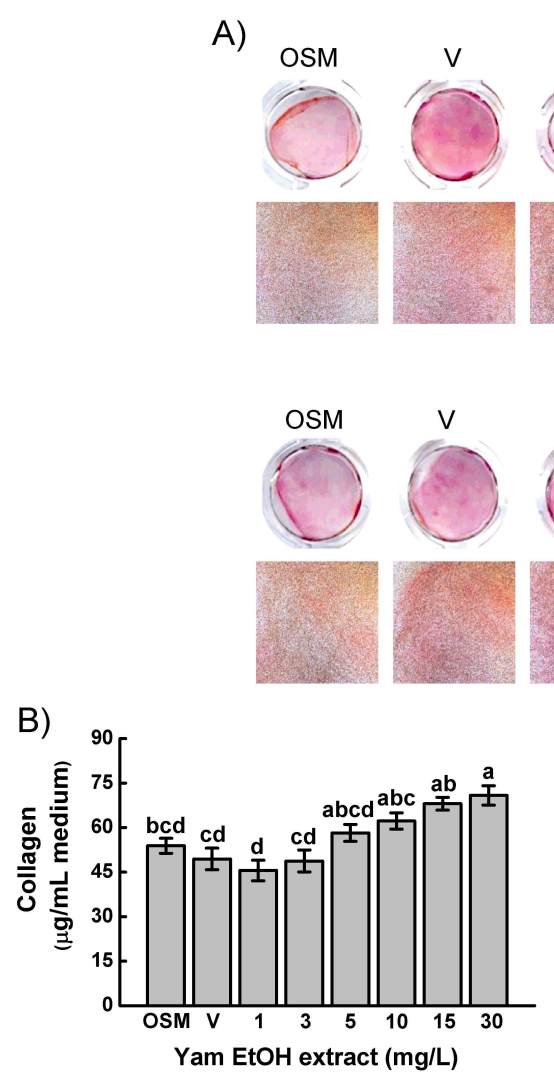

Yam EtOH extract (mg/L)

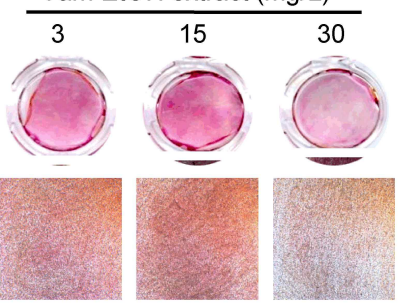

Yam $\mathrm{H}_{2} \mathrm{O}$ extract (mg/L)
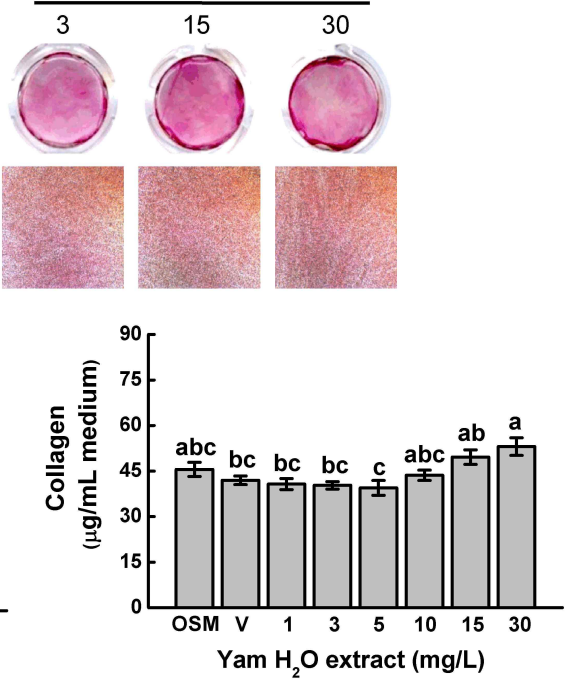

Fig. 3. Collagen accumulation in the extracellular matrix by yam ethanol and water extracts (A) and medium collagen quantification (B). (A) The effect of yam ethanol and water extracts on the collagen accumulation for mineralization was assessed by staining. Matrix collagen shown as red stain intensity was stimulated by yam ethanol and water extracts in a dose-dependent (between 0 as vehicle to $15 \mathrm{mg} / \mathrm{L}$ ) manner. (B) Cells were treated with yam ethanol and water extracts for 39 days and medium collagen levels were measured by colorimetric method using Picro-Sirius Red. Means having different superscripts indicate significant difference by yam extract treatment at $\mathrm{p}<0.05$ by ANOVA followed by Tukey's post hoc test $(\mathrm{n}=4)$. EtOH: ethanol, $\mathrm{H}_{2} \mathrm{O}$ : water, V: vehicle (with added solvent, ethanol only or water only). extract treatment (Fig. 3B, right panel). Yam ethanol extracts increased collagen accumulation more prominently within the range of $5 \sim 30 \mathrm{mg} / \mathrm{L}$, while yam water extracts was within $15 \sim 30 \mathrm{mg} / \mathrm{L}$ indicating that yam ethanol extract may be more potent in increasing collagen content for the collagen accumulation in cell matrix.

ALP activity stimulation and medium ALP activity

The influence of yam extracts on cell layer ALP activity in extracellular matrix was measured by ALP staining using Fast red salt as dye. ALP activity was more stimulated by yam ethanol extracts compared with yam water extracts (Fig. 4A). However, within the concentration range $(0 \sim 30 \mathrm{mg} / \mathrm{L})$ analyzed for both yam ethanol and water extracts, there was no observed dose-dependent ALP activity stimulation. The activity of ALP secreted in the medium was measured at 39 days treatment (Fig. 4B). Yam ethanol extracts slightly decreased media ALP activity while yam water extract did not show any significant change.

\section{DISCUSSION}

The balance between bone formation and resorption must be delicately maintained to ensure the integrity of the skeleton. So far, a number of studies show the potential of several dietary components and natural products in promoting bone formation and inhibiting bone re- sorption giving a net positive result on the skeleton. A wide range of dietary products with therapeutic effect on bone formation have been reported and several natural compounds have been shown to enhance osteogenic differentiation (9-13), such as red yeast rice (10), black cohosh (14), and green tea (13). The effect of yam extracts and their bioactive component on bone formation in vitro $(5,9,15)$, in vivo $(8,16-18)$, and in human population samples (19) have been reported and so far all showed potential in the treatment of bone-related diseases, particularly in osteoporosis.

However, in vitro studies on the effect of yam on bone formation via its effect on osteoblast proliferation and its effect on bone matrix proteins have been limited. Our previous study on diosgenin, one of the bioactive components extracted from yam, showed a positive role on bone formation via increasing the bone-specific transcription factor Runx2 as well as the bone matrix proteins type I collagen, ALP, and osteopontin (9). Thus, in the present study, we investigated the effect of yam ethanol and water extracts on the proliferation and bone matrix synthesis (type I collagen and ALP) using osteoblastic MC3T3-E1 cell model.

Bone formation is largely dependent on the executive cells and increasing osteoblast number could ensure that an efficient extracellular matrix is properly laid out for mineral matrix deposition, since the osteoblasts synthe- 

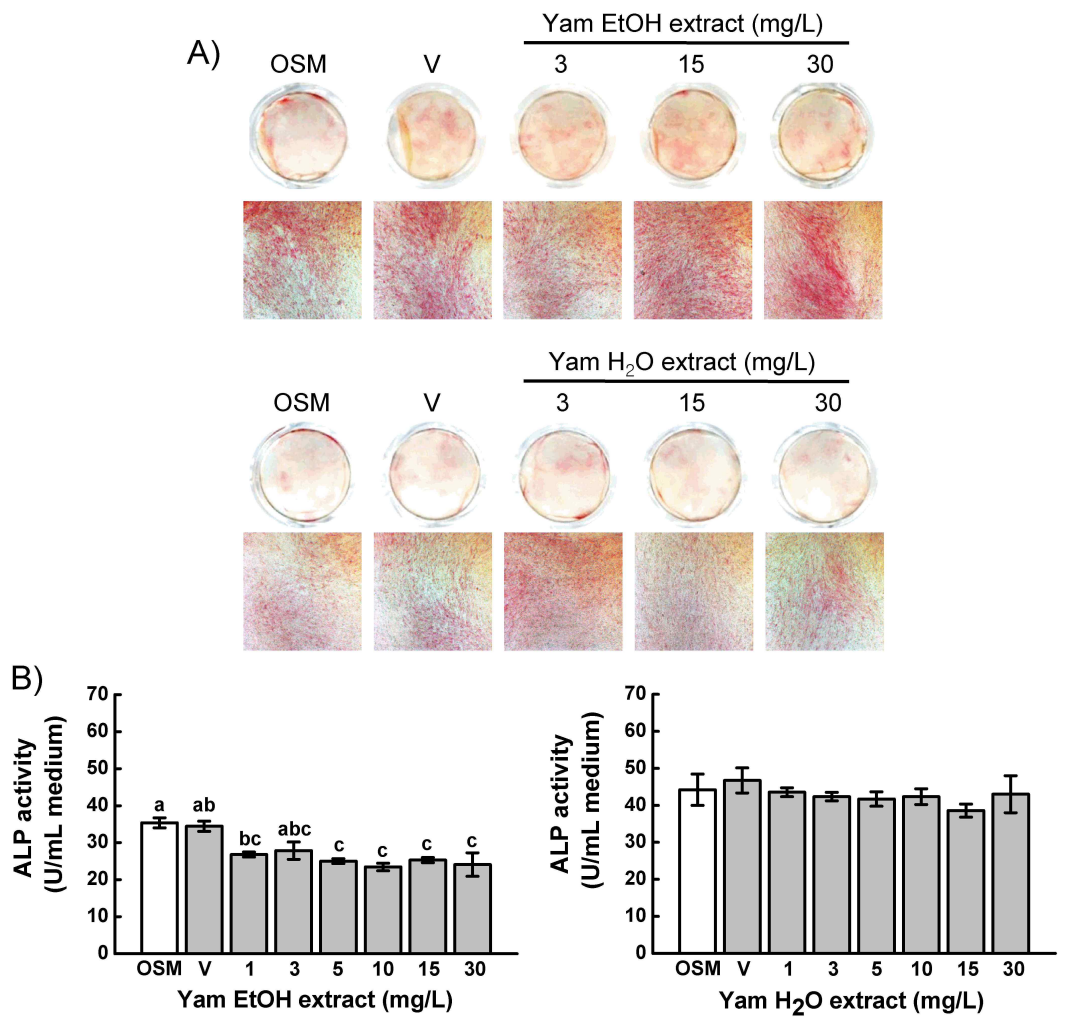

Fig. 4. Cell matrix ALP activity staining (A) by the treatment of yam ethanol and water extracts and medium ALP activity (B). (A) The effect of yam ethanol and water extracts on extracellular matrix ALP activity was measured by staining the products of enzyme activity in cellular layer. Yam extracts treatment did not prominently affect cell layer ALP activity. (B) Cells were treated with yam ethanol and water extracts for 39 days and medium ALP activity was measured by colorimetric method using PNPP as substrate. Media ALP activity by yam water extracts showed nonsignificant effect while yam ethanol extracts decreased ALP activity dose-dependently at 39 days. Means having different superscripts indicate significant difference between yam extracts at $\mathrm{p}<0.05$ by ANOVA followed by Tukey's post hoc test $(\mathrm{n}=4)$. EtOH: ethanol, $\mathrm{H}_{2} \mathrm{O}$ : water, V: vehicle (with added solvent, ethanol only or water only). size and secrete the bone matrix proteins. Hence, dietary compounds that could enhance osteoblast cell proliferation and differentiation are beneficial to bone formation. In the present study, we showed that both yam ethanol and water extracts increased cell proliferation indicating the ability of yam extracts to increase osteoblast number. This was observed at about 6 days to $13 \sim 15$ days of treatment which coincides with the osteoblast in vitro proliferation and differentiation stage, respectively. The increase in cell number in these stages may indicate that more cells can participate in the secretion bone matrix protein and synthesis of a collagen-rich extracellular matrix.

The formation of a collagen-rich extracellular matrix is crucial for mineralization since collagen serves as the structural scaffold to which minerals are later embedded in the matrix. About $90 \%$ of the extracellular matrix is made up of collagen (mainly type I collagen) and aside from its structural role, it also influences osteoblast structure, differentiation, and gene expression (20) and this may be likely mediated through the interaction of collagen with the heterodimeric integrin receptors (21). In the present study, we showed that both yam ethanol and water extracts could increase collagen accumulation in the extracellular matrix indicating a potential role of yam extracts in enhancing bone formation. Culturing of osteoblast cells without ascorbic acid, a cofactor for collagen synthesis, showed a fivefold reduction in ALP activ- ity and suppression of mineralization (20) which further emphasizes the crucial role of collagen synthesis in mineralization. Ascorbic acid stimulates procollagen hydroxylation and fibril assembly which is followed by robust induction of osteoblast associated genes including ALP (22).

Likewise, yam ethanol, but not water extracts, was found to slightly enhance ALP activity in the extracellular matrix, although no dose-dependent stimulation was observed. This may indicate that higher doses of yam extracts might be necessary to enhance ALP activity. ALP, a homodimeric metalloenzyme, is the most commonly used biochemical marker of an active osteogenesis. The ALP action on extracellular matrix mineralization is mainly degrading the ubiquitous mineralization pyrophosphate $(\mathrm{PPi})$ which releases inorganic phosphate (Pi) thus providing the necessary Pi for mineral nucleation process (23) and eventually inducing the formation of hydroxyapatite $\mathrm{Ca}_{10}\left(\mathrm{PO}_{4}\right)_{6}(\mathrm{OH})_{2}$ crystals within the collagen fibrils in the extracellular matrix. The expression of collagen and ALP activity are usually a coupled process, and an increase collagen accumulation may also indicate an increase in ALP activity since collagen scaffold is synthesized for mineralization and ALP can produce phosphate nucleator for $\mathrm{Ca}$ deposition into the collagen network. The crucial role of type I collagen and ALP on mineralization came from the works of Murshed et al. (24) who used several knock-out mouse models to 
demonstrate that the co-expression of collagen and ALP are necessary and sufficient to induce mineralization of any extracellular matrix. Therefore, the ability of yam extracts to enhance collagen accumulation in the extracellular matrix may indicate their positive role in enhancing bone formation.

In summary, our results suggest that yam ethanol and water extracts may have a potential positive effect in enhancing bone formation by 1) increasing osteoblast cell proliferation and 2) by increasing extracellular matrix collagen accumulation crucial for matrix mineralization. This study results may aid in the development of nutraceutical and functional food with the approach of utilizing yam extracts for the enhancement of bone health and prevention of bone-related disorders such as osteoporosis. Further studies are also needed to elucidate the potential mechanism whereby yam extracts affects bone formation so that a more effective treatment scheme may be developed.

\section{ACKNOWLEDGMENT}

This work was supported by High-Technology Development Project by ARPC (2008-2011), and for BaekDoo-Dae-Gan Green Mine Project by Ministry of Knowledge Economy (2011), Republic of Korea.

\section{REFERENCES}

1. Wang D, Christensen K, Chawla K, Xiao G, Krebsbach PH, Franceschi RT. 1999. Isolation and characterization of MC3T3-E1 preosteoblast subclones with distinct in vitro and in vivo differentiation/mineralization potential. $J$ Bone Miner Res 14: 893-903.

2. Rodan GA, Martin TJ. 2000. Therapeutic approaches to bone diseases. Science 289: 1508-1514.

3. Putnam SE, Scutt AM, Bicknell K, Priestley CM, Williamson EM. 2007. Natural products as alternative treatments for metabolic bone disorders and for maintenance of bone health. Phytother Res 21: 99-112.

4. Bharti AC, Takada Y, Aggarwal BB. 2004. Curcumin (diferuloylmethane) inhibits receptor activator of NF-kappa $\mathrm{B}$ ligand-induced NF-kappa B activation in osteoclast precursors and suppresses osteoclastogenesis. J Immunol 172: 5940-5947.

5. Yin J, Han N, Liu Z, Xu X, Zhang B, Kadota S. 2008. The in vitro anti-osteoporotic activity of some diarylheptanoids and lignans from the rhizomes of Dioscorea spongiosa. Planta Med 74: 1451-1453.

6. Yin J, Han N, Liu Z, Song S, Kadota S. 2010. The in vitro antiosteoporotic activity of some glycosides in Dioscorea spongiosa. Biol Pharm Bull 33: 316-320.

7. Yen ML, Su JL, Chien CL, Tseng KW, Yang CY, Chen WF, Chang CC, Kuo ML. 2005. Diosgenin induces hypoxia-inducible factor-1 activation and angiogenesis through estrogen receptor-related phosphatidylinositol 3-kinase/Akt and p38 mitogen-activated protein kinase pathways in osteoblasts. Mol Pharmacol 68: 1061-1073.
8. Higdon K, Scott A, Tucci M, Benghuzzi H, Tsao A, Puckett A, Cason Z, Hughes J. 2001. The use of estrogen, DHEA, and diosgenin in a sustained delivery setting as a novel treatment approach for osteoporosis in the ovariectomized adult rat model. Biomed Sci Instrum 37: 281-286.

9. Alcantara EH, Shin MY, Sohn HY, Park YM, Kim T, Lim JH, Jeong HJ, Kwon ST, Kwun IS. 2011. Diosgenin stimulates osteogenic activity by increasing bone matrix protein synthesis and bone-specific transcription factor Runx2 in osteoblastic MC3T3-E1 cells. J Nutr Biochem 22: 10551063.

10. Cho YE, Alcantara E, Kumaran S, Son KH, Sohn HY, Lee JH, Choi CS, Ha TY, Kwun IS. 2010. Red yeast rice stimulates osteoblast proliferation and increases alkaline phosphatase activity in MC3T3-E1 cells. Nutr Res 30: 501-510.

11. Kim MH, Shim KS, Lee SU, Kim YS, Min YK, Kim SH. 2010. Stimulatory effect of undecylenic acid on mouse osteoblast differentiation. Phytother Res 24: 559-564.

12. Maeda T, Matsunuma A, Kawane T, Horiuchi N. 2001. Simvastatin promotes osteoblast differentiation and mineralization in MC3T3-E1 cells. Biochem Biophys Res Commun 280: 874-877.

13. Shen CL, Yeh JK, Cao JJ, Wang JS. 2009. Green tea and bone metabolism. Nutr Res 29: 437-456.

14. Sethi G, Aggarwal BB. 2007. Mending the bones with natural products. Chem Biol 14: 738-740.

15. Peng KY, Horng LY, Sung HC, Huang HC, Wu RT. 2011. Antiosteoporotic activity of Dioscorea alata L. cv. Phyto through driving mesenchymal stem cells differentiation for bone formation. Evid Based Complement Alternat Med 29: 712892 .

16. Chiang SS, Chang SP, Pan TM. 2011. Osteoprotective effect of Monascus-fermented dioscorea in ovariectomized rat model of postmenopausal osteoporosis. J Agric Food Chem 59: 9150-9157.

17. Xing GS, Lou JS, Wang ZB, Yu SL, Wang Y, Sheng L. 2007. Effects of Dioscorea septemloba on bone metabolism in ovariectomized rats. Zhongguo Zhong Yao Za Zhi 32: 1909-1913.

18. Hsu KH, Chang CC, Tsai HD, Tsai FJ, Hsieh YY. 2008. Effects of yam and diosgenin on calpain systems in skeletal muscle of ovariectomized rats. Taiwan J Obstet Gynecol 47: 180-186.

19. Komesaroff PA, Black CV, Cable V, Sudhir K. 2001. Effects of wild yam extract on menopausal symptoms, lipids and sex hormones in healthy menopausal women. Climacteric 4: 144-150.

20. Lian JB, Stein GS. 1992. Concepts of osteoblast growth and differentiation: basis for modulation of bone cell development and tissue formation. Crit Rev Oral Biol Med 3: 269-305.

21. Lynch MP, Stein JL, Stein GS, Lian JB. 1995. The influence of type I collagen on the development and maintenance of the osteoblast phenotype in primary and passaged rat calvarial osteoblasts: modification of expression of genes supporting cell growth, adhesion, and extracellular matrix mineralization. Exp Cell Res 216: 35-45.

22. Wu X, Itoh N, Taniguchi T, Hirano J, Nakanishi T, Tanaka K. 2004. Stimulation of differentiation in sodium-dependent vitamin $\mathrm{C}$ transporter 2 overexpressing MC3T3-E1 osteoblasts. Biochem Biophys Res Commun 317: 1159-1164.

23. Balcerzak M, Hamade E, Zhang L, Pikula S, Azzar G, Radisson J, Bandorowicz-Pikula J, Buchet R. 2003. The 
roles of annexins and alkaline phosphatase in mineralization process. Acta Biochim Pol 50: 1019-1038.

24. Murshed M, Harmey D, Millan JL, McKee MD, Karsenty
G. 2005. Unique coexpression in osteoblasts of broadly expressed genes accounts for the spatial restriction of ECM mineralization to bone. Genes Dev 19: 1093-1104.

(Received December 14, 2011; Accepted December 16, 2011) 